\title{
Comparison of cone-beam computed tomography, clinical and surgical analysis for detection of maxillary molar furcation
}

\author{
Paula R. D. Oliveira', Thiago O. Sousa², José Valladares-neto³, João Antônio C. Souza', \\ Maria A. G. Silva', Virgílio M Roriz' \\ 1. Universidade Federal de Goiás, Faculdade de Odontologia, Departamento de Estomatologia, Goiânia, Brasil \\ 2. Centro de Diagnóstico Odontológico por Imagem, Goiânia, Brasil \\ 3. Universidade Federal de Goiás, Faculdade de Odontologia Departamento de Reabilitação Oral, Goiânia, Brasil
}

\begin{abstract}
The aim of this study was to compare the performance of conebeam computed tomography (CBCT), clinical and surgical probing in assessing maxillary molar furcation involvement (FI). Furcation defects $(n=120)$ were assessed through CBCT, clinical and intra-surgical evaluation (ISE). Furcation Involvement, vertical and horizontal bone loss were assessed through clinical probing, CBCT and probing during ISE. Three trained radiologists evaluated $C B C T$ images and intra- and interobserver agreement were calculated by Kappa test and Intraclass Correlation Coefficient (ICC). McNemar and Wilcoxon tests were used to compare clinical probing, ISE and CBCT. Accuracy, sensitivity, specificity, positive and negative predictive values were calculated to detect FI. Clinical findings showed 28 sites with Degree I, 25 sites with Degree II, and 8 sites with Degree III. Good intra- $(k=1.00)$ and interobserver agreement $(k=0.773)$ were observed. Intraobserver and interobserver
\end{abstract}

agreement for horizontal bone loss were moderate, $k=0.485$ and $k=0.549$, respectively. Intra-surgical findings showed Degree I at 21 sites, and Degree II and Degree III FI at fifteen sites each. Clinical evaluation showed $75 \%$ agreement with ISE and $78 \%$ with CBCT. Accuracy for clinical detection of FI was $75 \%$, while for CBCT evaluation ranged from $72.5 \%$ to $77.5 \%$, considering the 3 observers. Significant differences were found at distal sites using $C B C T(p<0.05)$.

Clinical evaluation and $C B C T$ showed similar results for the presence or absence of FI. Concerning horizontal and vertical bone loss, CBCT was not considered a precise examination method for incipient bone defects.

Received: April 2021; Accepted: October 2021

Keywords: cone-beam computed tomography - furcation defect - periodontal disease.

\section{Comparação da avaliação clínica, cirúrgica e por tomografia computadorizada de feixe cônico na detecção de lesões de furca em molares superiores}

\begin{abstract}
RESUMO
Este estudo teve como objetivo comparar o desempenho da tomografia computadorizada de feixe cônico (TCFC), sondagem clínica e cirúrgica na avaliação do envolvimento da furca de molares superiores $(E F)$. Defeitos de furca $(n=120)$ foram avaliados por meio de TCFC, avaliação clínica e intra-cirúrgica (IC). O envolvimento da furca, perda óssea vertical e horizontal foram avaliados através de sondagem clinica, TCFC e sondagem durante IC. Três radiologistas treinados avaliaram as imagens de TCFC e a concordância intra e interobservador foi calculada pelo teste Kappa e Coeficiente de Correlação Intraclasse (ICC). Para comparação da sondagem clínica, IC e CBCT foram utilizados os testes de McNemar e Wilcoxon. A precisão, sensibilidade, especificidade, valores preditivos positivos e negativos foram calculados para a detecção de EF. Os achados clínicos mostraram 61 sítios com EF, sendo 28 Grau I, 25 locais de Grau II e 8 locais de Grau III. Observou-se boa concordância intra- $(k=1,00)$ e interobservador $(k=0,773)$.
\end{abstract}

A concordância intraobservador e interobservador para perda óssea horizontal foi moderada, $k=0,485$ e $k=0,549$, respectivamente. Os achados intra-cirúrgicos mostraram EF grau I em 21 sitios e grau II e grau III em quinze sítios cada. A avaliação clínica mostrou $75 \%$ de concordância com IC e $78 \%$ com CBCT. A acurácia para detecção clínica de EF foi de 75\%, enquanto para avaliação de CBCT variou de $72,5 \%$ a $77,5 \%$, considerando os 3 observadores. Diferenças significativas foram encontradas em sitios distais em CBCT $(p<0,05)$.

A avaliação clínica e a TCFC mostraram resultados semelhantes para a presença ou ausência de EF. Em relação à perda óssea horizontal e vertical, a TCFC não foi considerada um exame preciso para defeitos ósseos incipientes.

Palavras-chave: tomografia computadorizada de feixe cônico defeito de furca - doença periodontal. 


\section{INTRODUCTION}

Early detection of furcation involvement (FI) favors treatment success, preventing the progression of alveolar bone loss and loosening of teeth ${ }^{1,2}$. Periodontal diagnosis of furcation involvement is based on clinical, radiographic and intra-surgical probing of the furcation entrance. Although intra-surgical measurement is invasive, it has been considered the gold standard for classifying the extent of furcation involvement, especially in upper molars ${ }^{3}$. Despite its accuracy for FI diagnosis, intra-surgical measurement should only be used in specific cases, while the conservative approach (clinical and radiographic examinations) can be routinely performed ${ }^{4}$.

Periapical, interproximal and panoramic radiographs have been widely used as complementary examinations for periodontal disease diagnosis, primarily due to their easy acquisition, low cost and satisfactory resolution ${ }^{5,6}$. Even though intraoral radiographs are still the most frequently used technique for diagnosing $\mathrm{FI}^{7}$, they are often not precise, because two-dimensional radiographs may show overlapping roots, making it challenging to evaluate furcation lesions correctly ${ }^{8,9}$.

Due to the limitations of conventional radiographs, cone-beam computed tomography (CBCT) has been indicated for the diagnosis of FI, since it provides detailed information about periodontal tissue support and interradicular bone, which are fundamental components for treatment planning ${ }^{10,11}$. It is worth using CBCT in FI diagnosis in upper molars when surgical treatment is indicated ${ }^{2}$. CBCT is highly accurate for detecting furcation involvement, and has been extensively used for challenging diagnoses, such as Degree I or $\mathrm{II}^{12,13}$.

In vivo studies ${ }^{3,5,10,14,15}$ have shown the potential of 3D images compared to intra-surgical assessments for diagnosing FI in maxillary molars, but results are controversial regarding $\mathrm{CBCT}$ accuracy for this purpose. The aim of this study was therefore to compare CBCT images with clinical and intrasurgical analyses to diagnose maxillary molar furcation involvement.

\section{MATERIALS AND METHODS}

This was a prospective cross-sectional study, performed in full accordance with the World Medical Association Declaration of Helsinki and approved by the Institutional Review Board of Federal University of Goiás, Brazil
(\#67419517.4.0000.5083) and University Center of Anápolis (\#2.126.098). It was also registered by ReBEC (Brazillian Register for Clinical Trials - \#RBR-33mj49). This study followed the CONSORT guidelines for clinical trials.

To calculate the sample size, $83 \%$ mean agreement was considered, as previously reported ${ }^{3,5}$, performed at a significance level of $95 \%$, for a test power of $80 \%$, two-tailed. A number of 41 sites per analyzed group was determined. The following inclusion criteria were established: patients older than 18 years, with periodontitis in the upper molar indicated for surgical treatment. Exclusion criteria were teeth with caries, cervical resorption, fused roots, metallic crowns, amalgam restorations close to the alveolar bone crest and endodontic treatment; pregnant and/ or lactating women. The study group was comprised of 12 patients ( 8 men and 4 women), aged 40 to 55 years and diagnosed with periodontitis. A total 40 teeth, 120 sites, with or without FI, were included.

Patients received prior periodontal therapy, including oral hygiene instructions, scaling and root planing, and occlusal adjustment when necessary. The same periodontist performed examination and treatment for all patients.

\section{Clinical measurements}

The sites were classified according to the presence or absence of FI, and horizontal and vertical bone loss were measured. Horizontal bone loss was assessed with Nabers probe (PQ2N, Hu-Friedy, Chicago, IL, USA) on the distal, buccal and mesial sites, according to the classification system of Hamp et al. (1975) ${ }^{16}$. Vertical bone loss was evaluated with the North Carolina probe (PCPUNC-15, Hu-Friedy, Chicago, IL, USA), measuring the distance from cementoenamel junction (CEJ) and the bottom of the periodontal pocket at the center of the buccal surface ${ }^{17}$. The examiner had no access to the CBCT images.

\section{Intra-surgical measurements}

Intra-surgical evaluation (ISE) was considered the gold standard and was performed using the same parameters described previously (Fig 1). During ISE, the periodontist had no access to the previous clinical measurements or the CBCT images.

\section{Image acquisition and analysis}

All CBCT images were acquired with an i-CAT Cone Beam 3D Imaging System-Next Generation (Imaging 


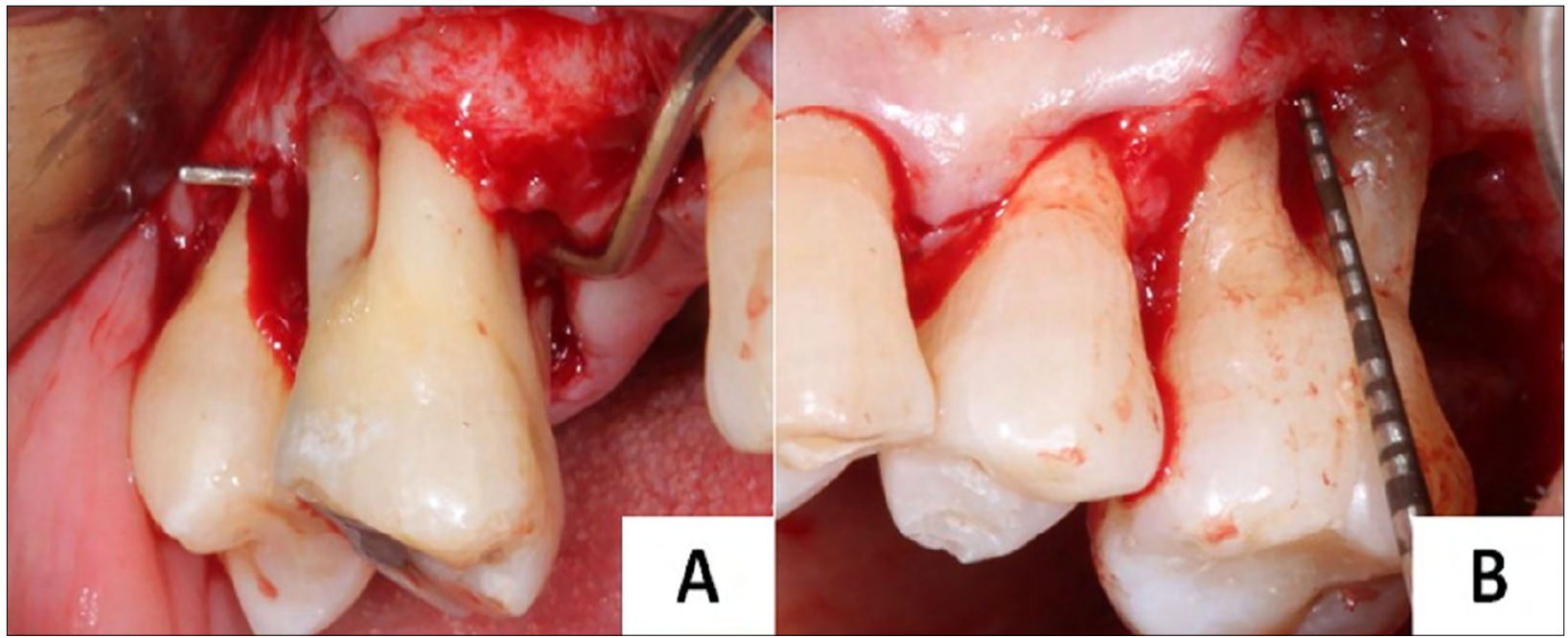

Fig. 1: Image of measurements made during intra-surgical assessment (gold standard). A) Horizontal assessment of the furcation involvement B) Vertical assessment in millimeters of the furcation lesion.

Sciences International, PA, USA) device using the same parameters: voxel size $0.125 \mathrm{~mm}^{3}$, tube setting $120 \mathrm{kV}$ (voltage) and $5 \mathrm{~mA}$ (current), acquisition time $26.9 \mathrm{~s}$, and an $8 \times 8 \mathrm{~cm}$ field of view (FOV). InVivo Dental Application software (Anatomage 5.3.2, USA) was used for CBCT image analysis.

Three previously calibrated radiologists performed the tomographic measurements. All the images were independently analyzed twice by each observer, with an interval of 2 weeks between the analyses.
The observers had no access to the clinical and intrasurgical evaluations. Horizontal and vertical bone loss were measured in the slice that showed the greatest extension of FI (Fig 2). Vertical measurements were performed in the sagittal plane by positioning the cursor at the beginning of the FI and extending it to the defect's maximum point (Fig 2D).

\section{Statistical analysis}

Cohen's Kappa test $(\kappa)$ was used to establish presence

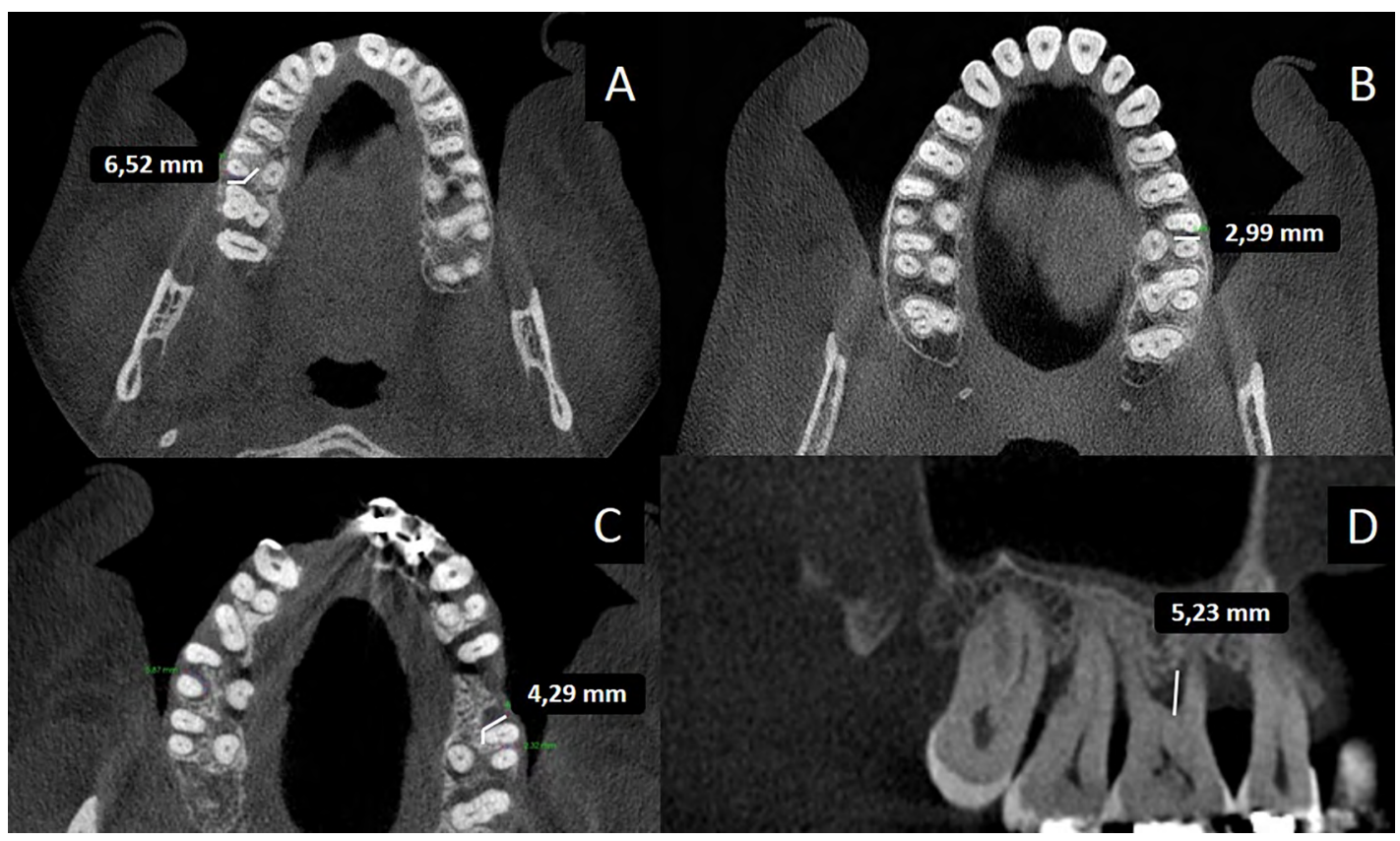

Fig. 2: Image of measurements made on CBCT images on software InVivo Dental Application. A) Horizontal measurement at distal site; B) Horizontal measurement at buccal site; C) Horizontal measurement at mesial site; D) Vertical measurement on buccal face. 
or absence of FI and horizontal bone loss. An Intraclass Correlation Coefficient (ICC) was used to analyze the intra- and inter-observer agreement in the tomographic measurements for vertical bone loss. For the Kappa test, the following interpretation was considered: $\mathrm{k} \leq 0.20$, poor; $\mathrm{k}=0.21-0.40$, fair; $\mathrm{k}=0.41-0.60$, moderate; $\mathrm{k}=$ $0.61-0.80$, good and $\mathrm{k}=0.81-1.00$, very $\operatorname{good}^{18}$. For the ICC interpretation, Bland and Altman's reference ${ }^{19}$ was used: ICC $<0.4$, small; $0.4 \leq \mathrm{ICC}<0.75$, moderate and ICC $\geq 0.75$, excellent.
Clinical and CBCT measurements (horizontal and vertical) were compared using the Wilcoxon test, which was also used to compare them to the gold standard (intra-surgical measurements). McNemar's test was used to compare the groups regarding the presence or absence of furcation involvement. Accuracy, sensitivity, specificity, positive and negative predictive values were calculated for the detection of furcation lesions.

\section{Table 1. Absolute frequencies and percentage (\%) of horizontal bone loss (Hamp et al. 1975) at the evaluated sites, according to different methods of assessment}

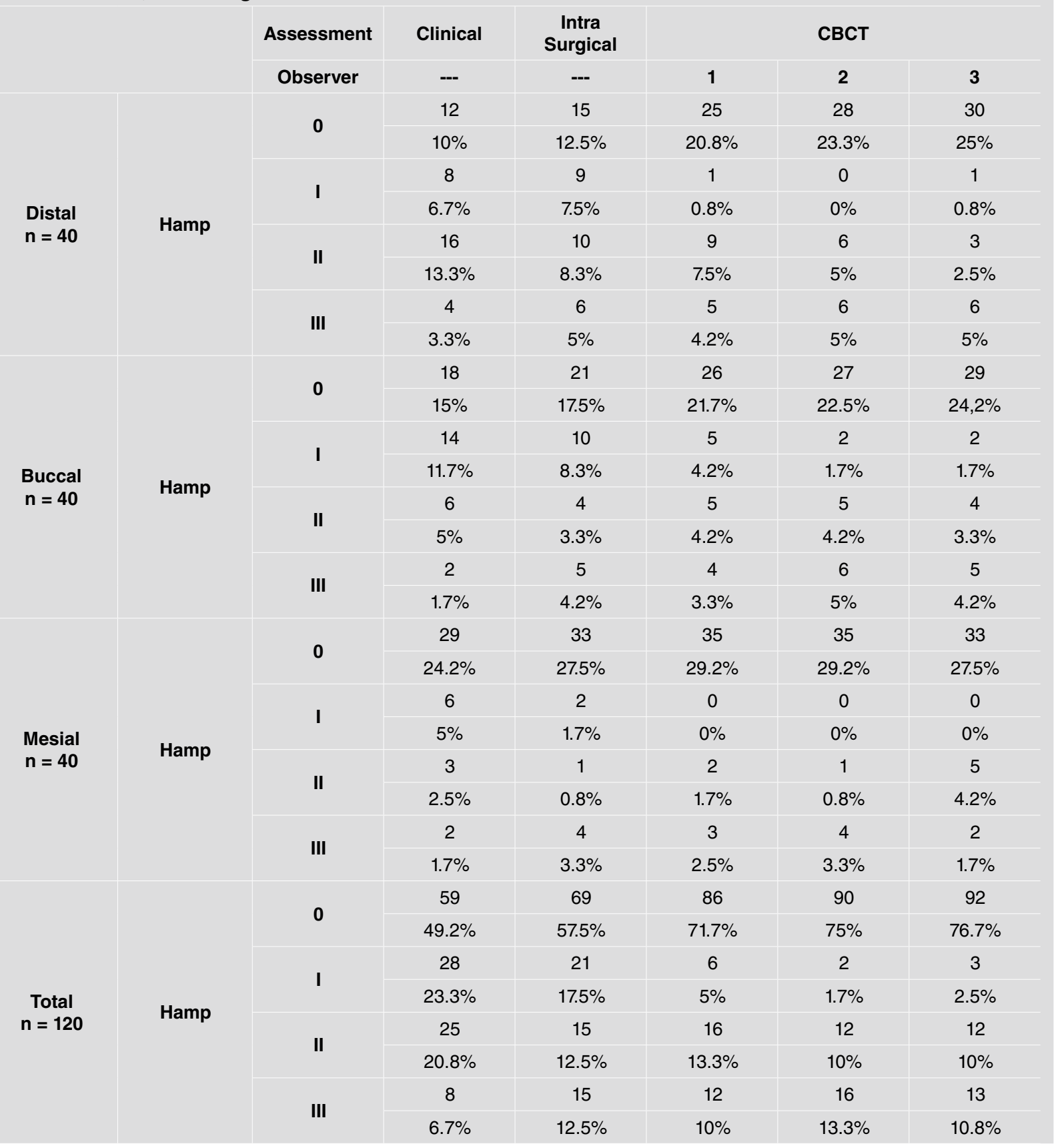




\section{RESULTS}

\section{Distribution of FI}

The horizontal FI recorded in the clinical, CBCT and intra-surgical evaluations are shown in Table 1. The intra-surgical findings revealed Degree I (21 sites), II (15 sites) and III (15 sites), while 69 sites showed no FI $(57.5 \%)$. The clinical findings presented 28 Degree I, 25 Degree II, and 8 Degree III lesions and 59 sites without FI (49.2\%). The CBCT findings showed 6 Degree I, 16 Degree II, and 12 Degree III lesions and 86 sites showed no FI (71.7\%).

Diagnostic tests for clinical and CBCT assessment Diagnostic tests for the detection of FI are shown in
Table 2. Accuracy for clinical detection was $75 \%$, while for CBCT evaluation it ranged from $72.5 \%$ to $77.5 \%$, considering the 3 observers.

Sensitivity was higher for CBCT (92.7\%) than for clinical evaluation $(72 \%)$, while specificity was lower for CBCT $(45.1-56.9 \%)$ than for clinical detection of FI (78.8\%).

\section{Intra- and inter-observer agreement on CBCT images}

Intra- and inter-observer agreement for the presence or absence of FI and horizontal bone loss are shown in Table 3 and those for the vertical bone loss in Table 4.

\begin{tabular}{|c|c|c|c|c|c|c|}
\hline & Observer(s) & Accuracy & Sensitivity & Specificity & PPV & NPV \\
\hline Clinical & - & 75 & 72 & 78.8 & 81.7 & 68.3 \\
\hline \multirow[t]{3}{*}{ СВСТ } & 1 & 77.5 & 92.7 & 56.9 & 74.4 & 85.3 \\
\hline & 2 & 74.2 & 92.7 & 49 & 71.1 & 83.3 \\
\hline & 3 & 72.5 & 92.7 & 45.1 & 69.6 & 82.1 \\
\hline
\end{tabular}

\begin{tabular}{|c|c|c|c|c|c|}
\hline Agreement & Observer(s) & Assessment & Kappa & $P$ value & Agreement \\
\hline \multirow{6}{*}{ Intra-observer } & \multirow{2}{*}{1} & $\begin{array}{l}\text { Presence or } \\
\text { absence }\end{array}$ & 1 & $<0.001^{*}$ & Very good \\
\hline & & $\begin{array}{l}\text { Horizontal bone } \\
\text { loss }\end{array}$ & 1 & $<0.001^{*}$ & Very good \\
\hline & \multirow{2}{*}{2} & $\begin{array}{l}\text { Presence or } \\
\text { absence }\end{array}$ & 0.895 & $<0.001^{*}$ & Very good \\
\hline & & $\begin{array}{c}\text { Horizontal bone } \\
\text { loss }\end{array}$ & 0.901 & $<0.001^{*}$ & Very good \\
\hline & \multirow{2}{*}{3} & $\begin{array}{l}\text { Presence or } \\
\text { absence }\end{array}$ & 1 & $<0.001^{*}$ & Very good \\
\hline & & $\begin{array}{l}\text { Horizontal bone } \\
\text { loss }\end{array}$ & 0.485 & $<0.001^{\star}$ & Moderate \\
\hline \multirow{6}{*}{ Inter-observer } & \multirow[b]{2}{*}{$1 \times 2$} & $\begin{array}{l}\text { Presence or } \\
\text { absence }\end{array}$ & 0.702 & $<0.001^{*}$ & Good \\
\hline & & $\begin{array}{l}\text { Horizontal bone } \\
\text { loss }\end{array}$ & 0.590 & $<0.001^{\star}$ & Moderate \\
\hline & \multirow[b]{2}{*}{$1 \times 3$} & $\begin{array}{l}\text { Presence or } \\
\text { absence }\end{array}$ & 0.697 & $<0.001^{*}$ & Good \\
\hline & & $\begin{array}{c}\text { Horizontal bone } \\
\text { loss }\end{array}$ & 0.549 & $<0.001^{*}$ & Moderate \\
\hline & \multirow[b]{2}{*}{$2 \times 3$} & $\begin{array}{l}\text { Presence or } \\
\text { absence }\end{array}$ & 0.773 & $<0.001^{*}$ & Good \\
\hline & & $\begin{array}{c}\text { Horizontal bone } \\
\text { loss }\end{array}$ & 0.625 & $<0.001^{\star}$ & Good \\
\hline
\end{tabular}


Table 4. Intra- and interobserver agreement for vertical bone loss

\begin{tabular}{|c|c|c|c|c|}
\hline Agreement & Observer(s) & ICC & $P$ value & Agreement \\
\hline \multirow{3}{*}{ Intra-observer } & 1 & 0.916 & 0.155 & -------- \\
\hline & 2 & 0.947 & 0.124 & ------- \\
\hline & 3 & 0.896 & 0.145 & ------- \\
\hline \multirow{3}{*}{ Interobserver } & $1 \times 2$ & 0.942 & $<0.001^{*}$ & Excellent \\
\hline & $1 \times 3$ & 0.922 & $<0.001^{*}$ & Excellent \\
\hline & $2 \times 3$ & 0.928 & $<0.001^{*}$ & Excellent \\
\hline
\end{tabular}

ICC - Intraclass Correlation Coefficient

*Statistical significance for ICC

For vertical bone loss, both intra-observer agreement $(\mathrm{ICC}=0.916) \quad$ and inter-observer $\quad(\mathrm{ICC}=0.965)$ agreement were considered excellent. Regarding the presence or absence of FI, intra-observer agreement was very good $(\mathrm{k}=1.000)$ and inter-observer agreement was good $(\mathrm{k}=0.773)$. Horizontal bone loss showed moderate $(\mathrm{k}=0.485)$ to very good $(\mathrm{k}=1.000)$ intra-observer agreement and moderate $(\mathrm{k}=0.549)$ to good $(\mathrm{k}=0.625)$ inter-observer agreement.

Comparison and agreement of clinical, CBCT and Intra-surgical assessment

Table 5 shows statistically significant results for the comparison and agreement tests between the clinical and CBCT data measurements and intra-surgical evaluations for all variables: presence or absence of FI and horizontal and vertical bone loss.

Comparing clinical and ISE, there was a significant difference between presence and absence of FI with moderate $(\mathrm{k}=0.501)$ and poor $(\mathrm{k}=0.442)$ agreement, respectively, for horizontal bone loss and very good $(\mathrm{k}=0.940)$ agreement for vertical bone loss $(\mathrm{p}<0.05)$. Comparing CBCT to ISE, there was a significant difference for the presence or absence of FI on CBCT to distal sites with moderate agreement for all assessments $(\mathrm{p}<0.05)$. Horizontal bone loss showed poor agreement with CBCT assessment $(p<0.05)$.

Table 5. $P$ values for comparisons and agreement between clinical and CBCT with intra-surgical measurements (gold-standard) at the evaluated site

\begin{tabular}{|c|c|c|c|c|c|c|c|c|c|}
\hline Measure & Assessment & Observer & Distal & Buccal & Mesial & All sites & $\begin{array}{l}\text { Kappa } \\
\text { or ICC }\end{array}$ & $p$-value & Classification \\
\hline \multirow{4}{*}{$\begin{array}{l}\text { Presence } \\
\text { or } \\
\text { absence of } \\
\text { furcation } \\
\text { lesion }\end{array}$} & Clinical & --- & 0.508 & 0.549 & 0.344 & 0.100 & 0.501 & $<0.001^{\star \star \star}$ & Moderate \\
\hline & \multirow{3}{*}{ СВСТ } & 1 & $0.006^{*}$ & 0.227 & 0.625 & $0.002^{*}$ & 0.519 & $<0.001^{\star \star \star}$ & Moderate \\
\hline & & 2 & $0.002^{*}$ & 0.109 & 0.625 & $<0.001^{*}$ & 0.441 & $<0.001^{\star \star \star}$ & Moderate \\
\hline & & 3 & $<0.001^{*}$ & $0.039^{*}$ & 1 & $<0.001^{*}$ & 0.402 & $<0.001^{\star \star \star}$ & Moderate \\
\hline \multirow{4}{*}{$\begin{array}{l}\text { Horizontal } \\
\text { bone loss }\end{array}$} & Clinical & -- & 0.297 & 0.837 & 0.658 & 0.442 & 0.364 & $<0.001^{\star * *}$ & Poor \\
\hline & \multirow{3}{*}{ СВСТ } & 1 & 0.050 & 0.195 & 0.608 & $0.028^{* *}$ & 0.364 & $<0.001^{\star * *}$ & Poor \\
\hline & & 2 & $0.005^{\star \star}$ & 0.782 & 0.467 & $0.030^{\star \star}$ & 0.367 & $<0.001^{\star \star \star}$ & Poor \\
\hline & & 3 & $0.003^{\star *}$ & 0.128 & 0.914 & $0.004^{\star *}$ & 0.297 & $<0.001^{\star \star *}$ & Poor \\
\hline \multirow{4}{*}{$\begin{array}{c}\text { Vertical } \\
\text { bone loss }\end{array}$} & Clinical & --- & --- & 0.907 & --- & --- & 0.940 & $<0.001^{\star \star \star *}$ & Very good \\
\hline & \multirow{3}{*}{ СВСТ } & 1 & --- & 0.084 & --- & -- & 0.487 & $<0.001^{\star \star \star \star}$ & Moderate \\
\hline & & 2 & -- & 0.116 & --- & --- & 0.740 & $<0.001^{\star \star \star *}$ & Moderate \\
\hline & & 3 & --- & $0.028^{\star \star}$ & --- & --- & 0.540 & $<0.001^{\star \star \star \star}$ & Moderate \\
\hline \multicolumn{10}{|c|}{$\begin{array}{l}\text { * Statistical significance, McNemar test } \\
\text { ** Statistical significance, Wilcoxon test } \\
{ }^{* \star *} \text { Statistical significance, Kappa test } \\
{ }^{* * \star *} \text { ICC: Statistical significance, ICC test }\end{array}$} \\
\hline
\end{tabular}




\section{DISCUSSION}

Our results showed that neither clinical evaluation nor CBCT presented high agreement with the gold standard (intra surgical evaluation - ISE). Accuracy values for FI detection were below $80 \%$, which indicates that caution is required when prescribing and interpreting $\mathrm{CBCT}$ exams for this purpose. Other studies have reported high precision for CBCT for detection of $\mathrm{FI}^{2,20}$. Our study's accuracy results may be related to a sample of incipient furcation lesions, which are difficult to diagnose, even in imaging exams. In a previous study, Yusof et al. ${ }^{14}$ found no difference between clinical and intra-surgical evaluation; however, they evaluated molars (both upper and lower) with extensive bone losses. In another study ${ }^{15}$, CBCT measurements showed high agreement with ISE in evaluating incipient furcation defects, as in the present study, but assessment was made by a single observer, and a larger FOV was employed. It is essential to mention that these variations in the agreement (greater or lesser) between CBCT and ISE in these studies may occur due to changes in the parameters of the CBCT devices (such as FOV, voxel size, voltage), as has been shown in a recent study by Rinne et al. ${ }^{21}$.

In the present study, the descriptive analysis concerning presence of FI showed a 14.2\% underestimation by $\mathrm{CBCT}$. Similar results were found in other clinical studies ${ }^{3,5,10}$. Clinical assessment overestimated presence of FI in $11.96 \%$ of the cases, showing superior results compared to CBCT. Our results differed from Darby et al. ${ }^{1}$, who found in clinical assessments an overestimation of $58 \%$ of FI and an underestimation of $20 \%$ of FI compared to CBCT.

The findings of the intra-observer agreement for the presence and absence of FI and horizontal bone loss were considered very good. These results were better than those reported in a previous in vitro study by Kolsuz et al. ${ }^{22}$, who found good agreement. It is important to emphasize that in vivo studies present difficulties related to soft tissue and anatomical variations ${ }^{7}$. This makes our results surprisingly better than those of in vitro studies in which these limitations are not present ${ }^{8,23}$.

For horizontal bone loss, the good and moderate interobserver agreement supports the notion that observers have difficulty in classifying FI compared to detecting presence or absence of the defect. Other clinical studies ${ }^{2,20,24}$ did not report the results of the interobserver agreement on CBCT, so we could not compare our findings.

There was no statistically significant difference regarding intra-observer agreement for vertical bone loss; however, inter-observer agreement was excellent. These results show the validity and reproducibility of CBCT in monitoring the height of the bone defect at the buccal surface of teeth with vertical bone loss.

As observed in this study, the distal site was diagnosed better $(p<0.05)$ than the buccal and mesial sites. These results corroborate Walter et al. ${ }^{2}$, who found a greater diagnostic precision at the distal site. Similar results were also described by Qiao et al. ${ }^{20}$, who reported significant agreement in the diagnosis of FI by ISE. Moreover, the study by Zhang et al. ${ }^{25}$, CBCT showed more significant agreement in the detection of distal sites by clinical evaluation, while in the recent study by Komšić, et al. ${ }^{15}$, the buccal site was better diagnosed than the distal and mesial sites.

In the present study, the general agreement of CBCT with intra-surgical assessment for the FI involvement was moderate $(\mathrm{k}: 0.519)$ and poor $(\mathrm{k}$ : 0.367 ) for horizontal bone loss. These results show that for the classification of bone loss, the statistical error of the method could have been relatively high. On the other hand, better results were found in the clinical studies by Qiao et al. ${ }^{20}$ and Walter et al. ${ }^{2}$, with very good agreement between CBCT and intrasurgical assessment, while Yusof et al. ${ }^{14}$ reported excellent agreement. Remarkably, these studies had samples with extensive FI, especially Degrees II and III, while in the present study, much of the sample consisted of incipient defects. In the early stages of FI, the cavities are small and have irregular borders, making them difficult to diagnose by $\mathrm{CBCT}^{26}$.

Moderate agreement was found upon comparing CBCT and ISE for vertical bone loss for all observers $(\mathrm{p}<0.05)$. Qiao et al. ${ }^{20}$ reported only the difference of $0.36 \mathrm{~mm}$ between the measurements, but not the agreement result. Padmanabhan et al. ${ }^{8}$ evaluated 25 furcation defects in lower molars, using a pachymeter for the evaluation of vertical bone loss, and found a difference of only $0.12 \mathrm{~mm}$ by CBCT compared to ISE. The differences found in those studies are small compared to the present study, and both showed statistically significant differences ${ }^{8,20}$. However, Yusof et al. ${ }^{14}$ did not find statistically significant differences between CBCT 
and ISE measurements for vertical bone loss.

In our study, accuracy results for FI identification were similar for clinical assessment and CBCT evaluation by all three observers. Interestingly, despite the similar results, a statistical difference was found upon comparing clinical assessment and CBCT by McNemar's test. This can be clearly understood by the sensitivity and specificity findings individually. In the clinical evaluation, all diagnostic test results presented a balanced ratio between sensitivity (72\%) and specificity (78.8\%), which resulted in a $75 \%$ accuracy value. Contrarily, CBCT accuracy for all observers was defined by high sensitivity compensation combined with low specificity. This implies that CBCT showed a high performance in detecting the presence of FI $(92.7 \%$ sensitivity) but was not as useful to exclude false positive cases. These findings should be taken into consideration when indicating and interpreting a CBCT exam for this purpose.

According to the meta-analysis published by Haas et al. ${ }^{27}$, although there is moderate scientific evidence supporting the use of CBCT to assess furcation

\section{DECLARATION OF CONFLICTING INTERESTS}

The authors declare no potential conflicts of interest regarding the research, authorship, and/or publication of this article

\section{FUNDING}

None lesions and FI, it should not be considered the first choice. Other systematic reviews ${ }^{28,29}$ corroborate this analysis, stating that CBCT should be indicated for selected cases, considering a risk-benefit balance. These researchers agree with Yang et al. ${ }^{30}$ on that, depending on the types of periodontal bone defects, CBCT is not necessary since clinical assessment is sufficient for detecting and classifying these lesions. Another critical issue to be highlighted is that different CBCT settings and devices may influence image accuracy for FI detection ${ }^{21,31,32}$, and a small field of view should be preferred ${ }^{28}$.

In summary, clinical, CBCT and intra-surgical measurements showed similar results in assessing maxillary molar furcation involvement. Regarding horizontal and vertical bone loss analyses, CBCT was not found to be an accurate method for incipient lesions. For the diagnosis of incipient furcation lesions, clinical evaluation remains fundamental. The indication of CBCT should be made considering the radiation dose evaluation and the real benefits for diagnosis of the furcation involvement.

\section{CORRESPONDENCE}

Prof. Virgílio Moreira Roriz

Faculdade de Odontologia

Av. Universitária Esquina com $1^{\mathrm{a}}$ Avenida $\mathrm{s} / \mathrm{n}$, Setor Universitário

CEP: 74605-220 - Goiânia - Goiás - Brazil.

vmroriz@hotmail.com

X11, 2012. (Radiation Protection series). https://www. research.manchester.ac.uk/portal/en/publications/conebeam-ct-for-dental-and-maxillofacial-radiology--

6. American Academy of Periodontology. Task Force Report on the Update to the 1999 Classification of Periodontal Diseases and Conditions. J Periodontol 2015;86:835-838.

7. Bagis N, Kolsuz ME, Kursun S, Orhan K. Comparison of intraoral radiography and cone-beam computed tomography for the detection of periodontal defects: an in vitro study. BMC Oral Health 2015;64:1-8.

8. Padmanabhan S, Dommy A, Guru SR, Joseph A. Comparative Evaluation of Cone-beam Computed Tomography versus Direct Surgical Measurements in the Diagnosis of Mandibular Molar Furcation Involvement. Contemp Clin Dent 2017;8:439-445.

9. Du Bois AH, Kardachi B, Bartold PM. Is there a role for the use of volumetric cone beam computed tomography in periodontics? Aust Dent J 2012;57:103-108.

10. Pajnijara N, Kolte A, Kolte R, Pajnigara N, Lathiya V. 
Diagnostic accuracy of cone beam computed tomography in identification and postoperative evaluation of furcation defects. J Indian Soc Periodontol 2016;20:386-390.

11. Walter C, Schmidt JC, Dula K, Sculean C. Cone beam computed tomography (CBCT) for diagnosis and treatment planning in periodontology: A systematic review. Quintessence Int 2016;47:25-37.

12. Woelber JP, Fleiner J, Rau J, Ratka-Kruger P, Hannig C. Accuracy and usefulness of $\mathrm{CBCT}$ in periodontology: a systematic review of the literature. Int $\mathrm{J}$ Periodontics Restorative Dent 2018;38:289-297.

13. Avila-Ortiz G, De Buitrago JG, Reddy MS. Periodontal Regeneration-Furcation Defects: A Systematic Review from the AAP Regeneration Workshop. J Periodontol 2015;86:S108-130.

14. Yusof NAM, Noor E, Reduwan NH, Yusof MYPM. Diagnostic accuracy of periapical radiograph, cone beam computed tomography, and intrasurgical linear measurement techniques for assessing furcation defects: a longitudinal randomised controlled trial. Clin Oral Investig 2020; 25:923-932

15. Komšić S, Plančak D, Kašaj A, Puhar I. A Comparison of Clinical and Radiological Parameters in the Evaluation of Molar Furcation Involvement in Periodontitis. Acta Stomatol Croat 2019;53:326-336.

16. Hamp SE, Nyman S, Lindhe J. Periodontal treatment of multirooted teeth. Results after 5 years. J Clin Periodontol 1975;2:126-135.

17. Müller HP, Eger T. Furcation Diagnosis. J Clin Periodontol. 1999;26:485-498.

18. Landis JR, Koch GG. The measurement of observer agreement for categorical data. Biometrics 1977;33:159174.

19. Bland JM, Altman DG. A note on the use of the intraclass correlation coefficient in the evaluation of agreement between two methods of measurement. Comput Biol Med 1990;20:337-340.

20. Qiao J, Wang S, Duan J, Zhang Y, Qiu Y, Sun C et al. The accuracy of cone-beam computed tomography in assessing maxillary molar furcation involvement. J Clin Periodontol 2014;41:269-274.

21. Rinne CA, Dagassan-Berndt DC, Connert T, Müller-Gerbl $\mathrm{M}$, Weiger R, Walter C. Impact of CBCT image quality on the confidence of furcation measurements. J Clin Periodontol 2020;47:816-824.

22. Kolsuz ME, Bagis N, Orhan K, Avsever H, Demiralp KO. Comparison of the influence of FOV sizes and different voxel resolutions for the assessment of periodontal defects. Dentomaxillofac Radiol 2015;44:20150070.

23. Bagis N, Eren H, Kolsuz ME, Kurt H, Avsever A, Orhan K. Comparison of the burr and chemically induced periodontal defects using different field-of-view sizes and voxel resolutions. Dentomaxillofac Radiol 2018;125:260-267.

24. Walter C, Kaner D, Berndt DC, Weiger R, Zitzmann NU. Three-dimensional imaging as a pre-operative tool in decision making for furcation surgery. J Clin Periodontol 2009;36:250-257.

25. Zhang W, Foss K, Wang BY. A retrospective study on molar furcation assessment via clinical detection, intraoral radiography and cone beam computed tomography. BMC Oral Health 2018; 18:75.

26. Nanci A, Bosshardt DD. Structure of periodontal tissues in health and diseases. Periodontol 2000 2006;40:11-28.

27. Haas LF, Zimmermann GS, De Luca Canto G, FloresMir C, Corrêa M. Precision of cone beam CT to assess periodontal bone defects: a systematic review and metaanalysis. Dentomaxillofac Radiol 2018;47:1-16.

28. Nikolic-Jakoba N, Spin-Neto R, Wenzel A. Cone-beam computed tomography for detection of intrabony and furcation defects: asystematic review based on a hierarchical model for diagnostic efficacy. J Periodontol 2016;87:630-644.

29. Choi I GG, Cortes ARG, Arita EK, Georgetti MAP. Comparison of conventional imaging techniques and CBCT for periodontal evaluation: A systematic review. Imaging Sci Dent 2018;48:79-86

30. Yang J, Li X, Duan D, Bai L, Zhao L, Xu Y. Conebeam computed tomography performance in measuring periodontal bone loss. J Oral Sci 2019;61:61-66.

31. Braun X, Ritter L, Jervøe-Storm PM, Frentzen M. Diagnostic accuracy of CBCT for periodontal lesions. Clin Oral Investig 2014;18:1229-1236.

32. Kim DM, Bassir SH. When is cone-beam computed tomography imaging appropriate for diagnostic inquiry in the management of inflammatory periodontitis? an American Academy of Periodontology best evidence review. J Periodontol 2017;88:978-998. 